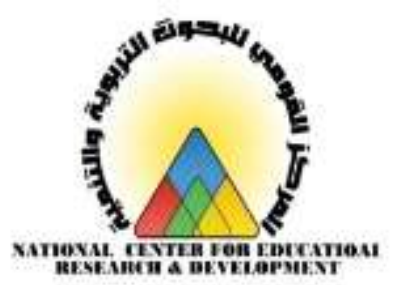

\title{
تأثير برنامج هقتزح باستخدام إحدى طرق \\ التسهيلات العصبية العضلية للمستقبلات \\ الصسية للمصابين بآلام أسفل الظهر
}

sld إعـــ

* محمود عبد الرازق محمد شطا

بكلية التربية الرياضية-جامعة بورسعيد

$$
\text { المكز التومي للبحوث التربوتتوالثميت بالتاهنة }
$$




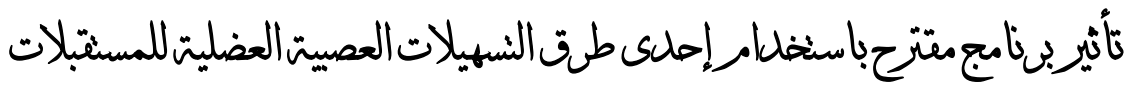
الحسيت للمعابينبآهر أسفل الظلهى

.$\leqslant 9$.

البحث التتربوي 


\section{المركن القومي للبحوث التبويةوالتنمية}

\section{تأثير برنامهج هقتزح باستفدام إحدى طرق التسهيلات الهصبية \\ العضلية للمستقبهلات المسية للمصابين بآلام أسفل الظهر \\ مستخلص الإحث:}

استهدف البحث تصميم برنامج يحتوي علي (تمرينات تأهيلية باستخدام إحدى طرق

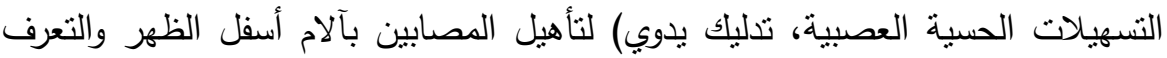

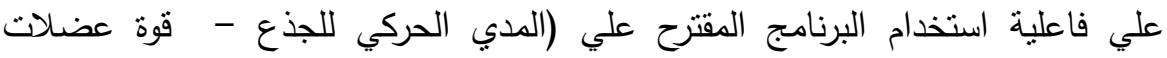

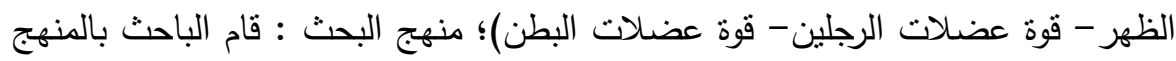
التجريبي وذلك نظرًا لملائمة هذه الدراسة من خلال التصميم التجريبي (القبلي _ البيني

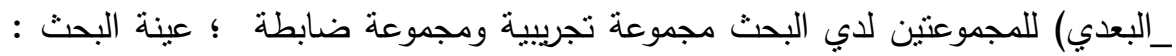

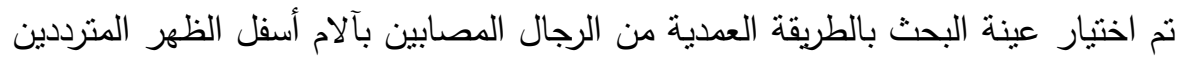

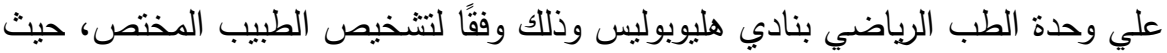

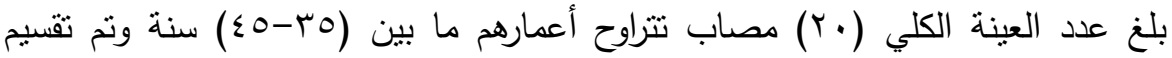

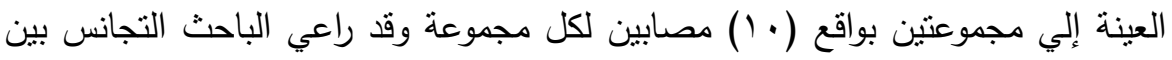
أفراد العينة من حيث الطول والوزن والسن وتم تطبيق البحث علي المجموعتين كما يلي: المجموعة التجريبية: وعددها (•) PNF مصابين ويطبق عليهم برنامج (تمرينات

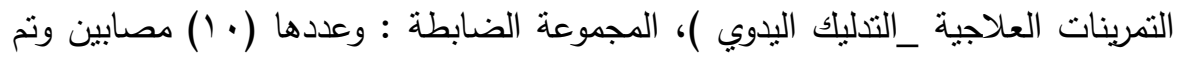

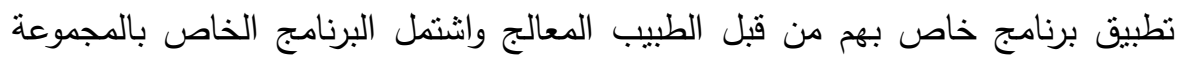
الضابطة علي ( أثعة تحت الحمراء _ الموجات فوق الصوتية _ تتبية كهربي _ تمرينات

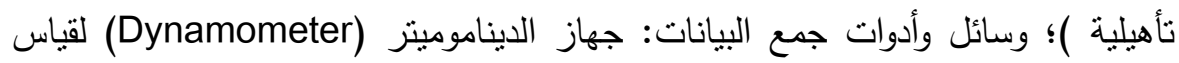

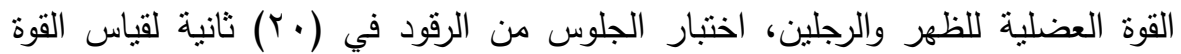

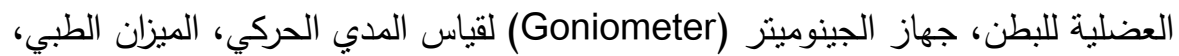

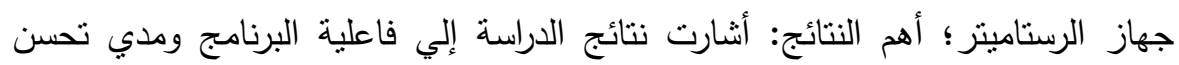

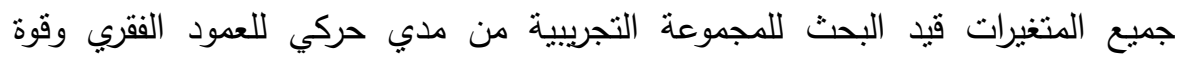

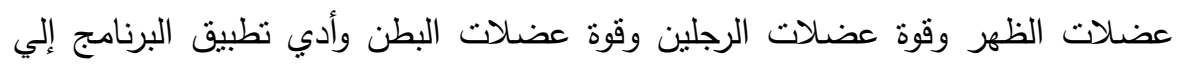
استعادة الوظائف الطبيعية للمنطقة القطنية. 


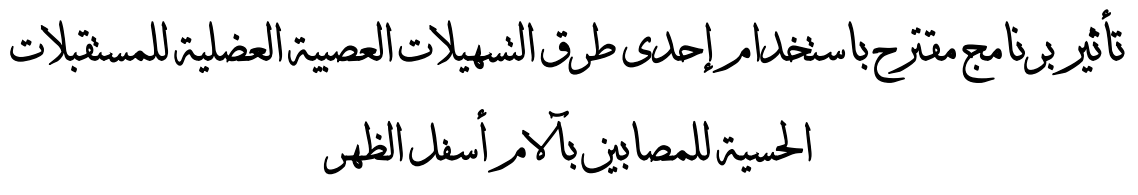

The Impact of a proposed program using one of the methods of Proprioceptive Neuromuscular facilities for Sensory receptors for people with lower back pain

Mr.Mahmouad AbdeRazeq Shata

Faculty of Education

PortSaid University

\section{Abstract}

The aim of the research is to design a program that contains (training exercises using one of the methods of sensory sensory facilities, hand massage) to rehabilitate those suffering from lower back pain and to identify the effectiveness of the proposed program on (the motor range of the trunk - strength of the muscles of the back - strength of the muscles of the two - The experimental method was chosen by the experimental method of men with low back pain, The total number of the sample (20) infected between the ages of (35-45) years and the sample was divided into two groups (10) infected each group has been sponsored by the researcher homogeneity among the sample members in terms of Height, weight, and age. The research was applied to the two groups as follows: The experimental group: the number of (10) infected and the program of ( $\mathrm{PNF}_{-}$exercises, therapeutic exercises, manual massage). The control group: (10) infected and a program of their own was applied by the physician. The control group (infrared) Ultrasonic analysis of the muscular strength of the back and legs, the sit-down test in 20 seconds to measure the muscular strength of the abdomen, the Goniometer device for measuring the motor range, The results of the study indicate the effectiveness of the program and the extent of improvement of all the variables under consideration for the experimental group of dynamic range of the spine and strength of the muscles of the back and strength of the muscles of the two men and the strength of abdominal muscles and the application of the program to restore normal functions of the lumbar region.

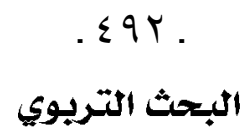




\section{المركن القومي للبحوثالتهبيةوالنمية}

\section{تأثير برناهج باستخدام إحدى طرق التسهيلات العصبية}

الهضلية للمستقبلات الهسية للمصابين بآلام أسفل الظهر

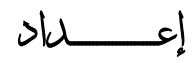

* محمود عبد الرازق محمد شطا

بكلية التربية الرياضية-جامعة بورسعيد

\section{الاقدهة ومشكلة البمث :}

وتتثير سميعه خليل (^ . ㄷ) انه لا يوجد سبب محدد للإصابة بآلام

أسفل الظهر وعلى الرغم من وجود هذه الإصابه عند العديد من عامة الناس،

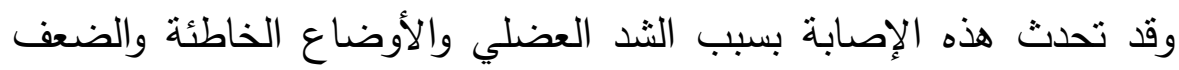

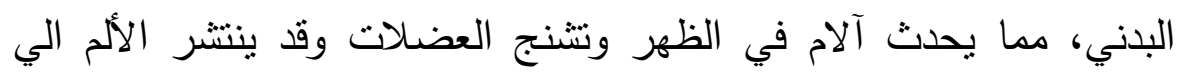
الأرداف والساقين، وتصاب عضلات أسفل الظهر بالضعف نتيجة الحد من استخدامها لتجنب الثعور بالآلام مما يسبب العيوب والتتوهات القوامية.

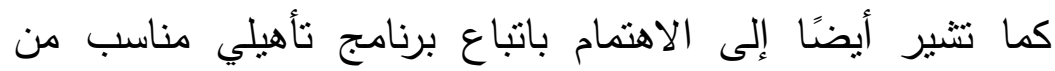

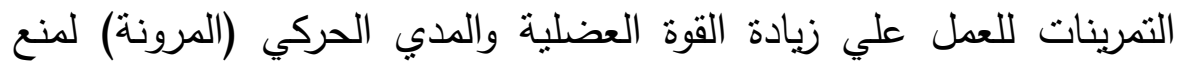
الصابة بآلام أسفل الظهر والاهتمام بالتدليك للعضلات المحيطة بمنطقة

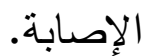

كمـا يؤكد قدري بكري وسـهام الغــري (0. ㄷ) ان هذه الإصـابة

تعتبر الثالثة من حيث الترتيب بين الرياضيين في جمهوريـة مصر العربية ويري كل من مارك والاس Mark Wallace وبيتر ستانس هets

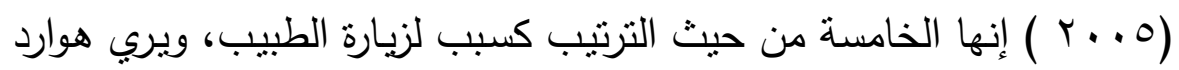




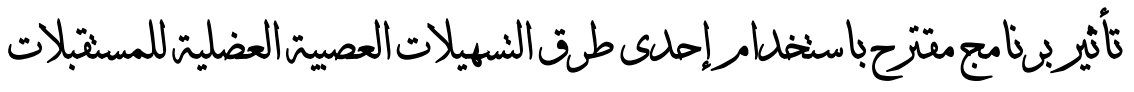
الحسيت للمعابينبآهر أسفل الظلهى

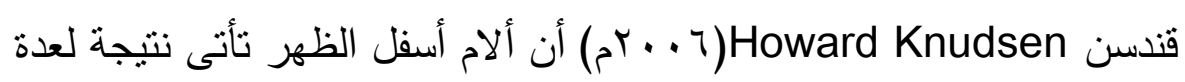

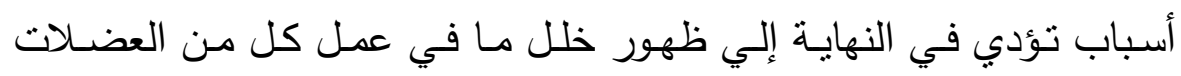

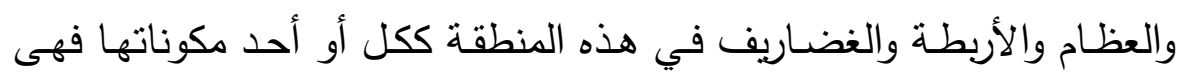

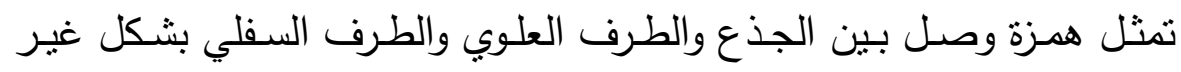

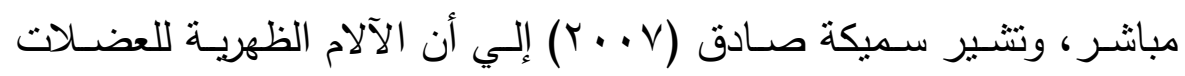

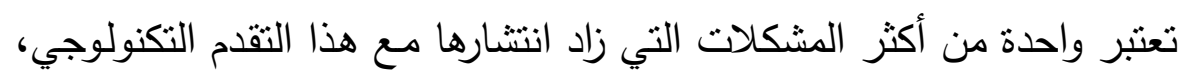

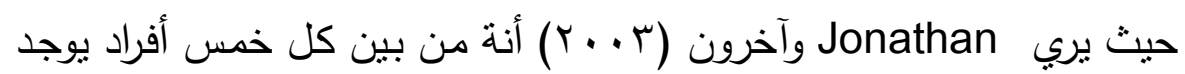
أربعة تعرضوا ولو لمرة واحدة لهذه المشكلة .

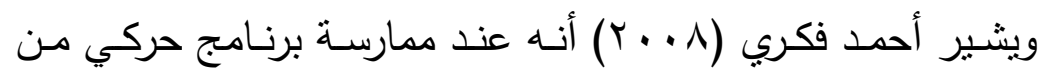

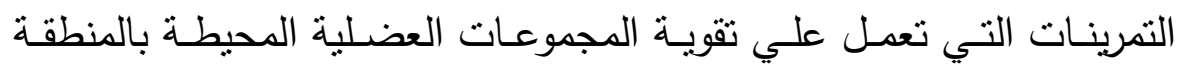

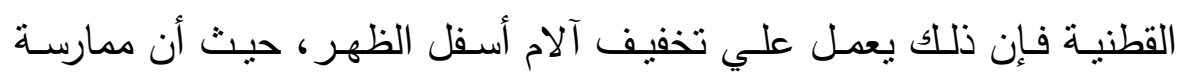

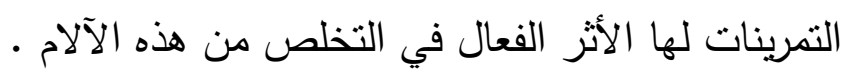

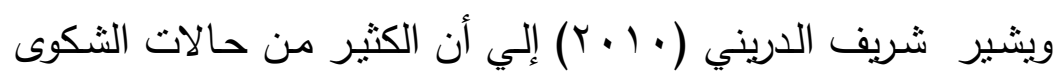

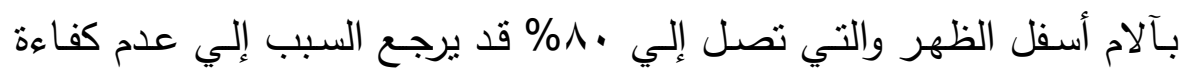

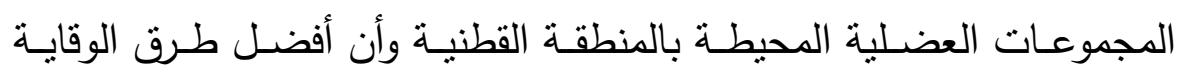

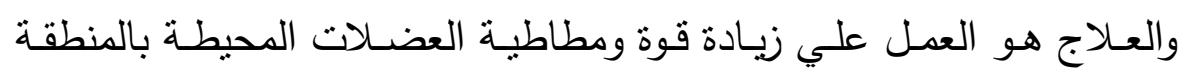
القطنية .

ويشير كلا من أبو العلا أحمد عبدالفتاح وأحمد نصر الدين سيد

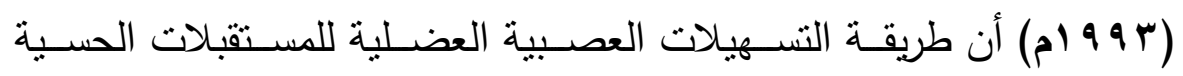
. $\leqslant 9 \leqslant$. 


\section{المركن القومي للبحوث التبويةوالتنمية}

\section{Proprioceptive neuro muscular facilitation ( PNF )}

طـرق تتميـة المرونـة والسـعة الانبسـاطية للعضـاتلات وتشـتمل تمرينـات تلكلك الطريقة علي استخدام انقباضات مستمرة لأزمنة محددة يتخللها استرخاء لتلك العضلات وتعتمد هذه الطريقة علي أسس فسيولوجية نرتبط بوظائف الأعضاء الحس حركيـة بالعضـلات حيث تتم عمليـة تنبيط لنشاط هذه الأعضـاء في العضـلة المطلـوب إطالتهـا وذلك لتقليـل عمليـة الأفعـال المنعكسـة المقاومـة لعملية إطالة العضلة مما يؤدي إلي زيادة المدى الحركي. وتعتبر تقنيـات أو أسـاليب إطالـة الـ PNF أكثر فاعليـة وتأثنيرًا مـن الاطالة القصرية البسيطة، وهذا التوفيق أو النجاح يمكن شرحه وتوضيحه عن طريق تأثير إطالة الـ PNF على المستقبلات الحسية داخل العضلة وتوتر العصب أو عضو وتر جولوجي والذى يتأثز بزيـادة المتانة أو الثدة داخل العضلة .

وفي الآونة الأخيرة بدأ العاملون في مجال التدريب الرياضي إلى

استخدام عمل المستقبلات الحسية والاعنماد على التركيب العصبي لها في تتمية عناصر اللياقة البدنية، وتعتمد هذه النوعية من التذريبات على مبدأ فسيولوجي أساسي يرتبط بالتسهيلات العصبية العضلية (P.N.F) التي توفرها المستقبلات الحسية المنعكسة من الجهاز الهيكلي. وتتمثل أهمية الاستعانة بنظام عمل المستقبلات الحسية أيضًا في مني الاستفادة من الافعال المنعكسة الناتجة عن الإطالة، وحدوث الأفعال المنعكسة الذي يتم عن طريق كل من المغازل العضلية التي تستجيب إلى 


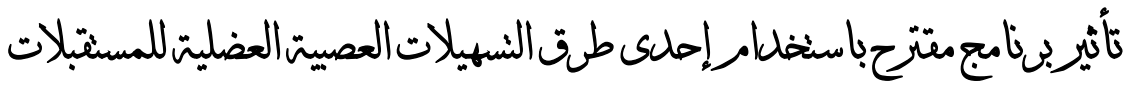
الحسيت للمصابينبآهر أسفل الظلهى

التغير الذي يحدث في طول العضلة ومعدل هذا التغير • هذا وبالإضافة إلى (GT) أعضاء جولجي الوترية (GTO) التي تساهم في زيادة نوتر العضلة وتلعب

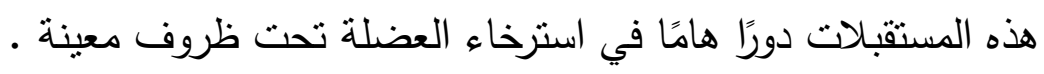

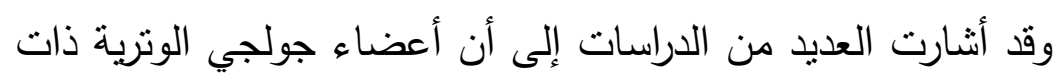

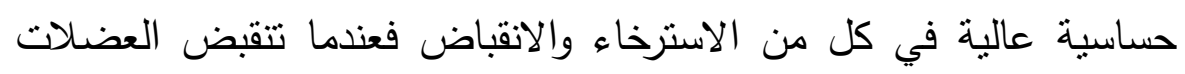

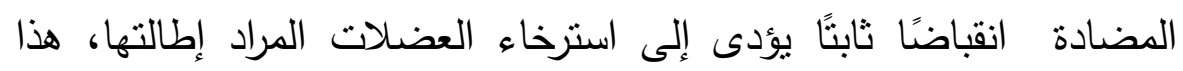

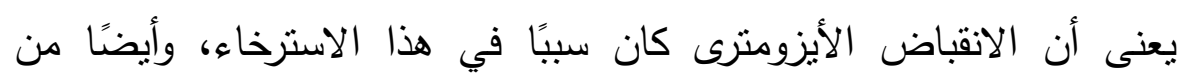

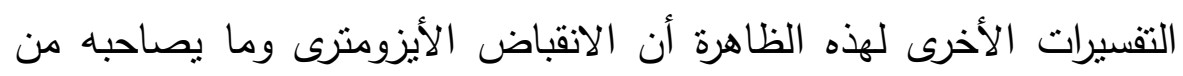

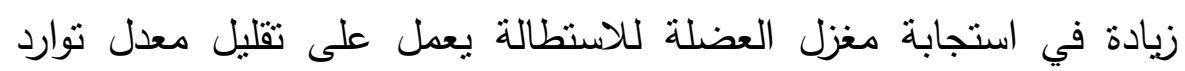

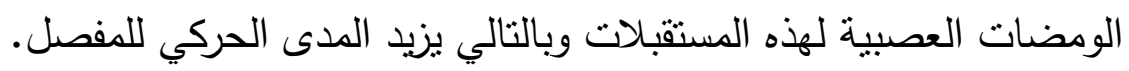

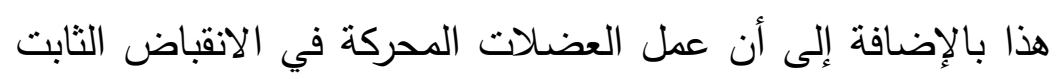

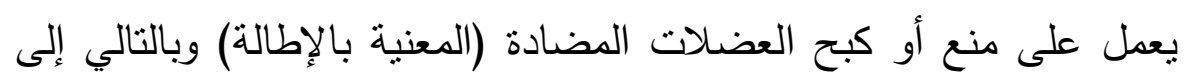

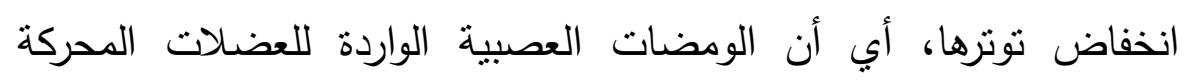
يصحبها زيادة نوتر هذه العضلات وفي نفس الوقت خفض ان الون التونر في العضلات المضادة .

وعند حدوث تحريك أو تتبيه عضو وتر جولجي Golgi، فإنه يتسبب فى حدوث استرخاء عضلى، وإذا حدث هذا الاسترخاء فى ذات العضلة فئلة فانة

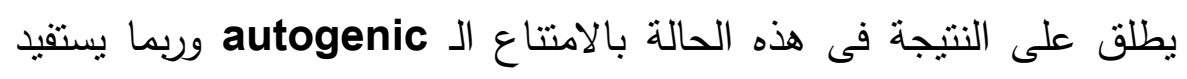
المدرب من ذلك الحادث الطبيعى وذللك عن طريق جعل اللاعب الرياضى بلى 


\section{المركن القومي للبحوث التبويةوالتنمية}

يقوم بعمل انقباض للعضلة مباشرة قبل الاطالة السلبية لنفس العضلة وهكذا أو بذلك يحدث ما يسمى بالمنع autogenic وفى هذا المثال فـإن الثـدة أو الأطالة النـاتج خـلال الانقباض ينبـه عصب عضدو وتر جولجي Golgi محدثًا استرخاء منعكس لنفس العضلة خلال الاطالة القصرية التالية، أما إذا حدث الاسترخاء فى العضلة المقابلة أو المضـادة للعضلة التى تم بها اختبار زيادة الثد أو الإطالة، فإن النتيجة هنا تسمى المنع أو الامتتاع المتبادل أو المشترك، وخلال الاطالة السلبى نجد أن

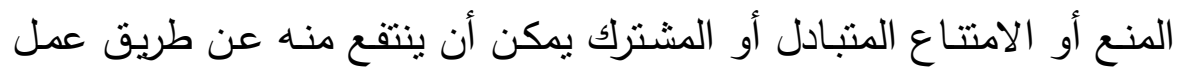
انقبـاض للعضـلة فى وقت واحد للعضـلة المقابلـة التى تم عمـل اطـالة لهـا والإطالـة أو الثـد فى العضـلة المنقبضـة يُحرك عصدب عضـو وتر جولجي Golgi ويعرف"Nelson نيلسون " (199 (م) (PNF بأن طرق المستقبلات العصبية العضلية هي إحدى طرق العلاج التي تعتمد على ميكانيزمات تساعد على التحفيز والتنيط الموجود طبيعيا في الجهاز العصبي. وتعتبر طريقة التسهيل العصبى العضلى للمستقبلات الحسية Proprioceptive Neuromuscalar facilitation (PNF) طرق لتتمية المرونة المفصلية والسعة الإنبساطية للعضلات ونتنمل تمرينات تلك الطريقة على استخدام انقباضات عضلية أيزومنرية متتالية في صور تكررات انقباضية مستمرة لأزمنة محددة يتخللها استرخاء لتلك العضلات أو مجموعات انقباضية يعقبها استرخاء وإطالة على تللك 


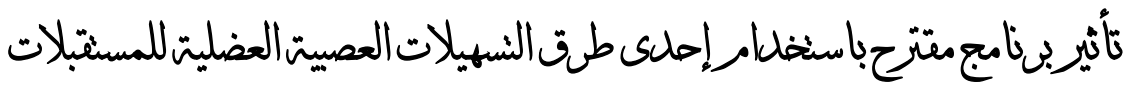
الحسيت للمعابينبآهر أسفل الظلهى

العضلات وتعتمد هذه الطريقة على أسس فسيولوجية ترتبط بوظائف الأعضاء في العضلة المطلوب إطالتها وذللك لتقليل عملية الأفعال المنعكسة المقاومة لعملية إطالة العضلة مما يزيد المدى الحركى وتؤدى الدى إلى زيادة المدى الحركى لها.

ومن ثم فقد سعي الباحث للتصدي لهذه المشكلة التي يعاني منها

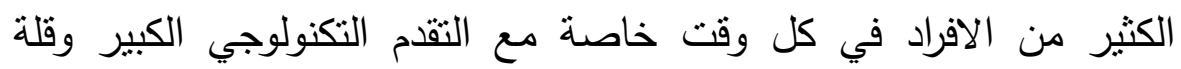
الممارسة الرياضية، وذلك من خلال عمل برنامج علاجي باستخدام احدي

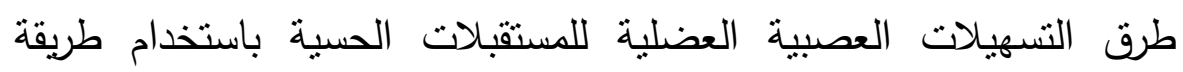
الانقباض والاسترخاء مما يساعد علي الوقاية من الإصابة بآلام اسفل الظهر بلهر

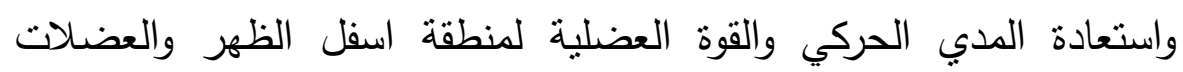

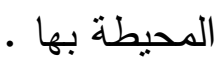

\section{يهذف البحث الي التعرف على :}

تأثير استخدام أحلى أساليب المستقبلات الحسية العصبية (PNF)

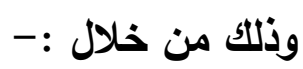
ا ـ تخفيف حدة الألم.

r. زيادة مرونة الجذع واستعادة المدي الحركي للمنطقة القطبية والعضلات المحيطة بها وعودة الكفاءة الوظيفية لمنطقة اسفل

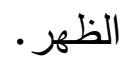
.$\Sigma 91$. البحث التربوي 


\section{المركن القومي للبحوث التبويةوالتنمية}

r. تقوية المجموعات العضلية في منطقة الظهر والبطن والعضلات

الخلفية للفخذ وزيادة تحملها .

فروض البمث :

ا. توجد فروق دالة إحصائًا للمجموعة الضابطة في القياس

القبلي والبيني الأول والبيني الثاني والقياس البعدي للقوة

$$
\text { العضلية لصالح القياس البعدي. }
$$

r. توجد فروق دالة إحصائيًا للمجموعة الضابطة في القياس

القبلي والبيني الأول والبيني الثاني والقياس البعدي للمدي

$$
\text { الحركي لصالح القياس البعدي. }
$$

r. توجد فروق دالة إحصائًا للمجموعة التجريبية في القياس

القبلي والبيني الأول والبيني الثاني والقياس البعدي للقوة

$$
\text { العضلية لصالح القياس البعدي. }
$$

ع. توجد فروق دالة إحصائًا للمجموعة التجربيية في القياس

القبلي والبيني الأول والبيني الثاني والقياس البعدي للمدي

$$
\text { الحركي لصالح القياس البعدي. }
$$

هـ توجد فروق دالة إحصائيًا بين المجموعة الضابطة والتجربيية

في القياس البعدي في القوة العضلية لصالح المجموعة

$$
\text { التجريبية. }
$$




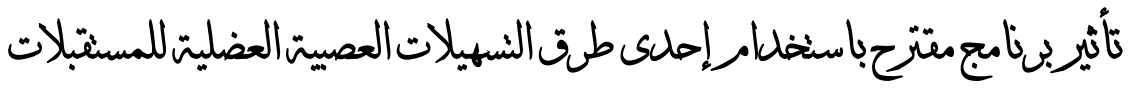
الحسيت للمعابينبآهر أسفل الظلهي

T. توجد فروق دالة إحصائيًا بين الدجموعة الضابطة والتجرييية

في القياس البعدي في الددي الحركي لصالح الدجموعة التجريبية.

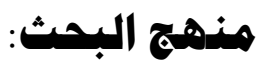

سوف يستخدم الباحث المنهج التجريبي بنطبيق القباسات القبلية

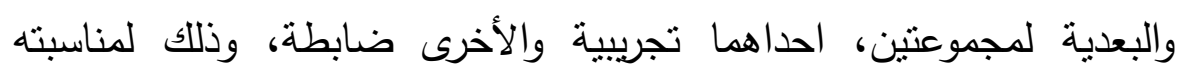

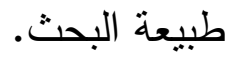

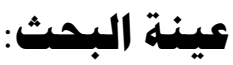

سوف يتم اختيار العينة بالطريقة العدية وتتمتل العينة للمصابين

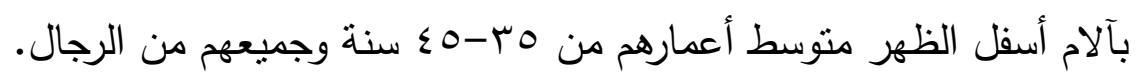
الإجراءات والوسائل المستخدهة:

ولإجراء هذه الدراسة قام الباحث بالخطوات النالية:

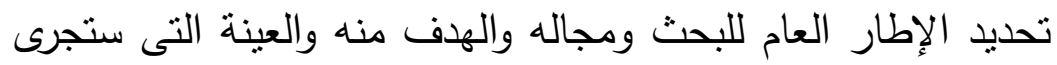

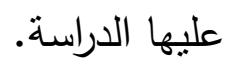

ه تحديد المراحل التى سيمر بها البحث.

تحديد الدنهج المستخذم بما يتناسب مع تحقيق أهداف البحث وتمشيًا مع طبيعتة ومحاولة النحقق من صحة الفروض. ضبط المتغيرات وتكافؤ المجموعتين التجريبية والضابطة. 


\section{المركن القومي للبحوث التبويةوالتنمية}

القيام ببعض الدراسات الاستطلاعية قبل البدء فى تطبيق البرنامج للتعرف على الصعوبات التى يمكن أن تواجه الباحث.

اختيار وتحديد وسائل القياس المستخدمة فى البحث ووسائل جمع البيانات المستخدمة فى قياس النتائج للمجموعتين، حيث قسمت هذه

$$
\text { الوسائل إلىى: - إلى }
$$

أ- استمارات إقرار بالموافقة على تطبيث البحث على عينة الدراسة.

$$
\text { جـ اختبارات لقباس القوة والمرونة لعينة البحث. }
$$

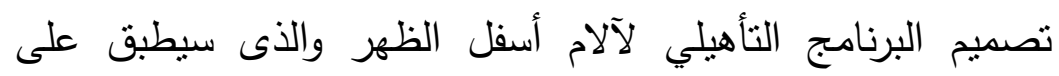
الجموعة التجريبية. تطبيق البرنامج الموضوع والقيام بالتأهيل حسب البرنامج الزمنى المعد لذلك حيث يتم تأهيل المجموعتين مع إضافة البرنامج المقترح لآلام أسفل الظهر للمجموعة التجربيية. 


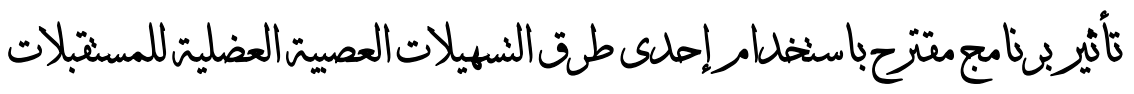
الحسيت للمصابينبآآهر أسفل الظلهى

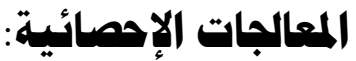

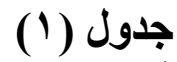

تكافؤ المجموعثين الضابطة والتجريبية في قياسات المدى الحركى والقوة

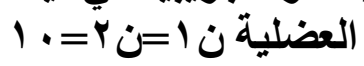

\begin{tabular}{|c|c|c|c|c|c|c|c|c|c|c|}
\hline \multirow{3}{*}{ 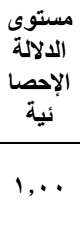 } & \multirow{3}{*}{$\frac{\mathbf{U}}{0 ., \ldots}$} & \multicolumn{2}{|c|}{ مجموع الفروق } & \multicolumn{2}{|c|}{ متوسط الفروق } & \multicolumn{2}{|c|}{ المجموعات } & \multirow{2}{*}{\multicolumn{2}{|c|}{ الإحصاء }} & \multirow{2}{*}{ م } \\
\hline & & ت & ت & ت & ت & ت & ت & & & \\
\hline & & $1.0, \ldots$ & $1.0, \ldots$ & $1 ., 0$. & $1 ., 0$. & 1. & 1. & لرألذام & & 1 \\
\hline$\cdot, r V$ & $r_{0,0}$. & $119,0$. & $9 ., 0$. & 11,90 & $9, .0$ & 1. & 1. & للخفلة الجذع & h & r \\
\hline •, & $\leq r, 0$. & $111,0$. & $9 \wedge, 0$. & 11,10 & $9, \wedge 0$ & 1. & 1. & الجأجناعن & $\underline{\underline{G}}$ & $r$ \\
\hline$\cdot, \wedge \wedge$ & $\varepsilon \Lambda, \cdots$ & $1 \cdot v, \ldots$ & $1 . r, \ldots$ & $1 \cdot, v \cdot$ & $1 \cdot, r$. & 1. & 1. & اللجانبع & & $\varepsilon$ \\
\hline$\bullet, \varepsilon$ & $r q, \ldots$ & $117, \ldots$ & $9 \leq, \ldots$ & $11,7$. & १, ६. & 1. & 1. & عضلات & & 0 \\
\hline$\cdot, I V$ & $r r, \ldots$ & Irr, . & $\wedge \vee, \ldots$ & Ir,r. & $\wedge, \vee$. & 1. & 1. & عضلات & 点. & 7 \\
\hline$\cdot, \wedge \bullet$ & $\leqslant V, 0$. & $1 \cdot r, 0$. & I. $v, 0$. & $1 \cdot, r_{0}$ & $1 \cdot, v 0$ & 1. & 1. & عضلات & 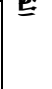 & v \\
\hline
\end{tabular}

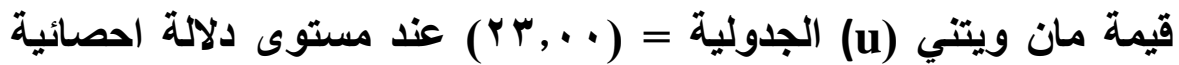
$(\cdot, \cdot \theta)$ 


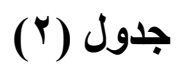

المتوسط الحسابي والانحراف المعياري في قياسات المدى الحركى والقوة العضلية للمجموعة المئي

الضابطة في القياسات القبلي والبينى الأول والثانى والبعدى

$$
\text { 1. }
$$

\begin{tabular}{|c|c|c|c|c|c|c|c|c|c|c|}
\hline \multicolumn{2}{|c|}{ البعدى } & \multicolumn{2}{|c|}{ القياس البينى الثانى } & \multicolumn{2}{|c|}{ القياس البينى } & \multicolumn{2}{|c|}{ القباس } & \multirow{2}{*}{\multicolumn{2}{|c|}{ القياسات }} & \multirow{2}{*}{ p } \\
\hline$\varepsilon \pm$ & س- & $\varepsilon \pm$ & س- & $\varepsilon \pm$ & س- س & $\varepsilon \pm$ & س- س & & & \\
\hline$r, \leqslant r$ & $r, v=$ & $r, \cdot r$ & r,o.. & $r, \leqslant \wedge$ & $\varepsilon, 1$. & r, & $\varepsilon, q$. & للأمامنة الجذع & \multirow{4}{*}{$\begin{array}{l}\underline{\underline{n}} \\
\underline{E} \\
\underline{E} \\
\underline{E}\end{array}$} & 1 \\
\hline 1,70 & $r v, 0$. & 1,74 & $r v, 1$. & $1, \wedge \vee$ & $r ४, \wedge$. & $r, \ldots$ & $r \uparrow, r$. & للخلف الجذع & & $r$ \\
\hline$r, £ 0$ & $1,, v$. & & $1,1,1$. & $r, r V$ & $9,0$. & YT, & $q, \ldots$ & للجاتب الايمن & & $r$ \\
\hline $1, \wedge q$ & $11, v$. & $r, 11$ & $11, \ldots$ & $1, \vee \wedge$ & $1,, \varepsilon$. & $r, \cdot r$ & q,v. & للجانب الايسر & & $\varepsilon$ \\
\hline \& & 70,1 . & & יז,זr & \&,rV & ז & \&,०V & ז., & قوظة عضلات & \multirow{3}{*}{ 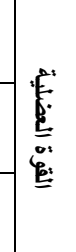 } & 0 \\
\hline $0, r r$ & $9 \%, r$. & 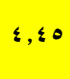 & $q, r$. & & $\wedge 9,1$. & \&,Y. & $\wedge \vee, \S$. & قالرجلين عضلات & & 1 \\
\hline$r, \leqslant 1$ & iv,r. & $r, \leqslant \leqslant$ & $17, \mathrm{r}$. & r,7q & $10,1$. & r, 79 & $1 r, q$. & قالبطن عضلات & & V \\
\hline
\end{tabular}




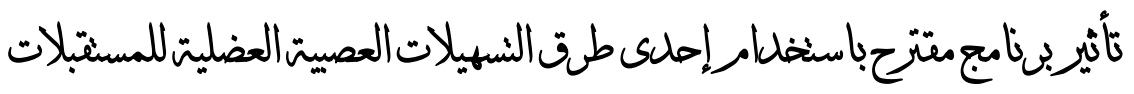
الحسيت للمطابينبآهر أسفل الظلهي

\section{جدول (")}

المتوسط الحسابي والانحراف المعياري في قياسات المدى الحركى والقوة

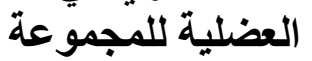
التجريبية في القياسات القبلي والبينى الأول والثانى و البعدى

$$
\text { 1. }
$$

\begin{tabular}{|c|c|c|c|c|c|c|c|c|c|c|}
\hline \multicolumn{2}{|c|}{ البعدى البياس } & \multicolumn{2}{|c|}{ القياس البينى } & \multicolumn{2}{|c|}{ القياس البينى الأول } & \multicolumn{2}{|c|}{ القباس القبي } & \multirow{2}{*}{\multicolumn{2}{|c|}{ القياسات الإحصاء }} & \multirow{2}{*}{ e } \\
\hline$\varepsilon \pm$ & س- & $\varepsilon \pm$ & س- & $\varepsilon \pm$ & س- & $\varepsilon \pm$ & س- & & & \\
\hline$r, \cdots$ & $\cdot, r$. & $r, 0$. & r, r.. & $r, \leqslant$ & $r, r .$. & $r, \varepsilon 1$ & $\varepsilon, q .$. & للأجمام & & 1 \\
\hline r,O० & $r 1, \gamma$. & $r, V r$ & $\Gamma_{\cdot,, \varepsilon}$ & $r, T \&$ & $\uparrow \wedge, q$. & $r, \leqslant 4$ & $r v, O$. & للخلف الجذع & $q_{n}$ & r \\
\hline $1, V Y$ & $1 \leqslant, 0$ & 1,74 & Ir,q. & $1, \wedge 9$ & $11, r$. & 1,99 & $৭, \wedge$. & للجانب الإنغ & 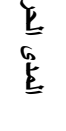 & $r$ \\
\hline $1,0 \mathrm{~V}$ & I $\leqslant, v$. & l, & $\mid r, r$. & 1,01 & $11,7$. & 1,10 & १,१. & اللجانب & & $\varepsilon$ \\
\hline 0,91 & $v_{4}, \ldots$ & 7,11 & $v \cdot, \wedge$. & 0,91 & . & $0, T$ & $r$ r., & قوة عضلات & & 0 \\
\hline $0, r \leqslant$ & $1.0,9$. & $0, r_{0}$ & $1 \ldots, v$. & $0,1 Y$ & १४, ४ & $0, \cdot 1$ & $9 ., 0$. & قوة عضلات & $\frac{E}{6}$ & 7 \\
\hline$r, \&$. & $r r,$. & r,rq & $19, \wedge$. & r.०q & 14,7 & r,OA & $1 \pi, v$. & قوة عضلات & & V \\
\hline
\end{tabular}


جدول (\&) ( )

دلالة الفروق بين المجموعتين الضابطة والتجريبية في قياسات المدى الحركى والقوة العضلية في القياس البعدى الفئي

ن

\begin{tabular}{|c|c|c|c|c|c|c|c|c|c|c|}
\hline \multirow{2}{*}{ الإلئلة } & \multirow{2}{*}{$\mathbf{U}$} & \multicolumn{2}{|c|}{ مجموع الفروق } & \multicolumn{2}{|c|}{ متوسط الفروق } & \multicolumn{2}{|c|}{ المجموعات } & \multirow{2}{*}{\multicolumn{2}{|c|}{ الإحصاء }} & \multirow{2}{*}{ r } \\
\hline & & ت & ت & تr & ت & ت & ت & & & \\
\hline$\cdot, \cdot r$ & rr,o. & Irr,o. & $\checkmark v, 0$. & Or, & $\mathrm{v}, \mathrm{v} 0$ & 1. & 1. & للأجمام & & 1 \\
\hline$\cdot, \cdots$ & $9,0$. & $1 \leqslant 0,0$. & $7 \leq, 0$. & $1 \leq 00$ & $7, \leqslant 0$ & 1. & 1. & للخلف الجذع & n & r \\
\hline$\cdot, \cdots$ & $1,, \ldots$ & $1 \leq 0, \ldots$ & $10, \ldots$ & $1 \leq 0$. & $7,0$. & 1. & 1. & الجزانب & $\begin{array}{l}E \\
E \\
E \\
E\end{array}$ & $r$ \\
\hline$\cdot, \cdots$ & $9, \ldots$ & $1 \leq 7, \ldots$ & $7 \leq, \ldots$ & $1 \leq, 7$. & ૫, ๕. & 1. & 1. & الجزانب & & $\varepsilon$ \\
\hline$\cdot, \cdots$ & $7,0$. & $1 \leqslant 1,0$. & $71,0$. & $1 \leq, \wedge 0$ & 7,10 & 1. & 1. & عضلات & & 0 \\
\hline$\cdot, \cdots$ & $\bullet, \ldots$ & $10, \ldots$ & $7, \ldots$ & $10, \ldots$ & ४,, & 1. & 1. & عضلات & ${ }^{\stackrel{E}{E}}$ & 9 \\
\hline$\cdot, \cdots$ & $1,0$. & $10 r, 0$. & 07,0 . & $10, r_{0}$ & 0,70 & 1. & 1. & عضلات & & v \\
\hline
\end{tabular}

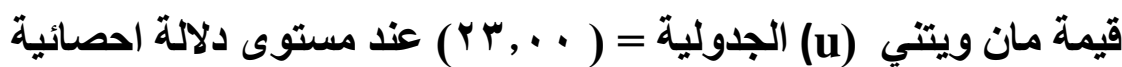
$(\cdot, \cdot, 0)$ 


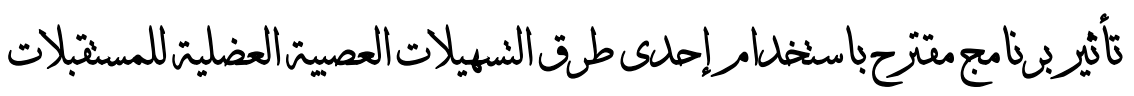
الحسيت للمعابينبآهر أسفل الظلهي

جدول (0)

النسبة المئوية للتحسن في قياسات المدى الحركي والقوة العضلية للمجمو عثين الضابطة والتجريبية مناقثة نتائج البحث :

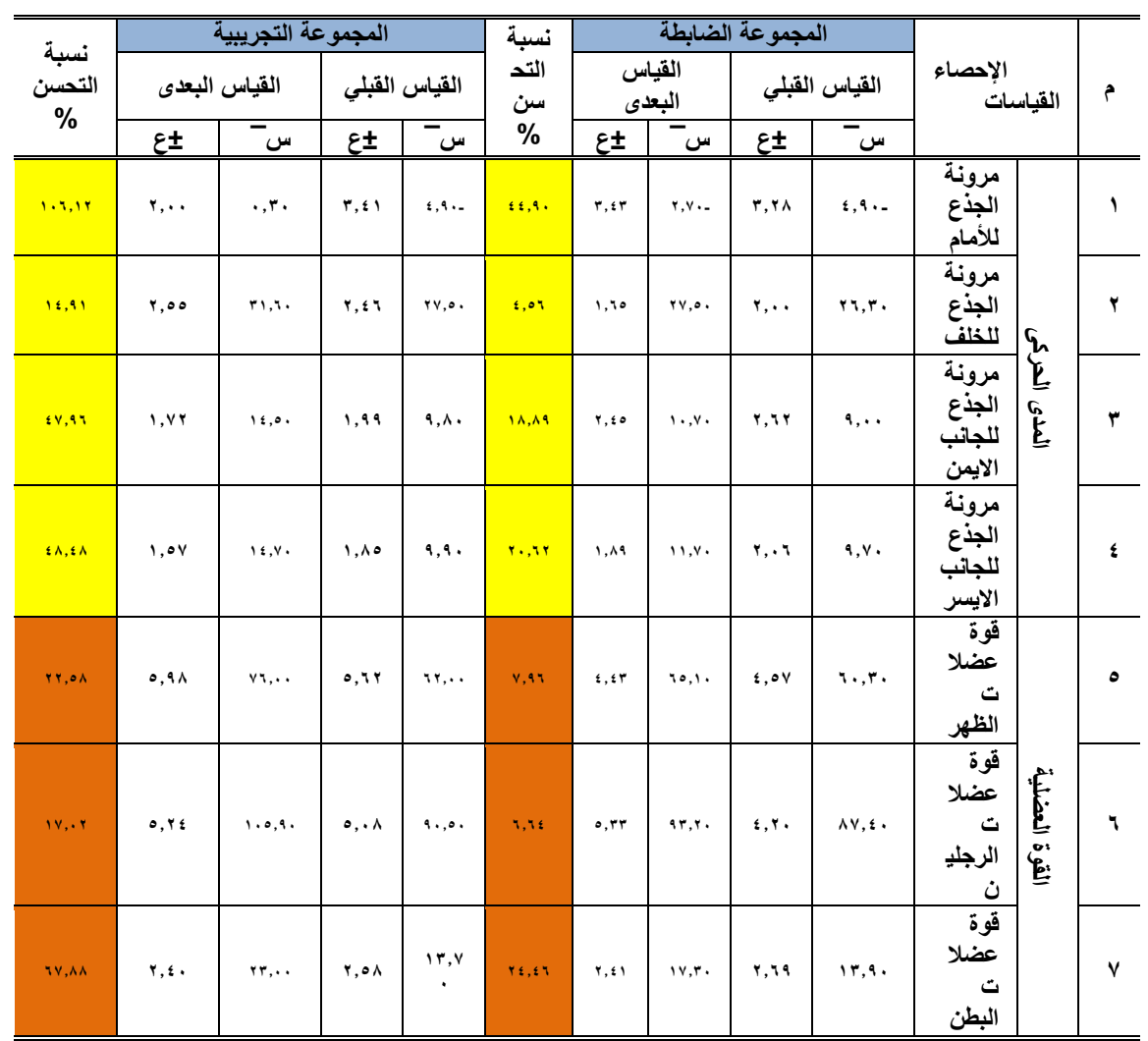

.0 .7 


\section{المركن القومي للبحوث التبويةوالتنمية}

يتضح من جدول (1) أن قيم مان ويتتي (u) لالالة الفروق بين

المجموعتين الضابطة والتجريبية أكبر من قيمة (u) الجدولية البالغة ( ) وأن قيم مستوي الدلالة الإحصائية أكبر من مستوى الدلالة الإحصائية ( . .00) مما بدل علي عدم وجود فروق ذات دلالة إحصائية بين المجموعتين الضابطة والتجريبية وتكافؤهما في تلك القياسات، كما أظهرت نتائج جدول (ع) الخاص بدلالة الفروق بين المجموعتين الضابطة والتجربيية في قياسات المدي الحركي والقوة العضلية في القياس البعدي عند مستوي الدلالة الإحصائية (...00) مما يدل علي وجود فروق ذات دلالة إحصائية بين المجموعتين الضابطة والتجريبية ولصالح المجموعة التجريبية في قياسات المدي الحركي والقوة العضلية حيث جاءت نسبة التحسن في للمجموعة الضابطة في قياسات المدي الحركي قد تراوحت من (70،؛ء)إلي (•9،؛ء؟)

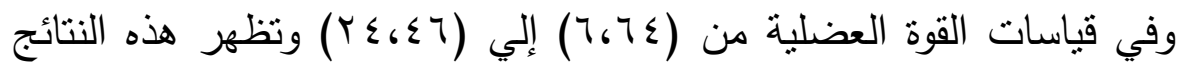
للمجموعة الضابطة لإخضاعها لبرنامج تقليدي من بعض التمرينات التأهيلية مما أدي إلي تحسنهم بينما بلغت نتائج المجموعة التجربيية بقيم أفضل من المجموعة الضابطة حيث تراوحت نتائجها في قياسات المدي الحركي من

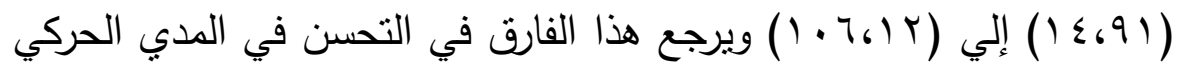
إلي إخضاع المجموعة التجربيية إلي تتفيذ البرنامج التأهيلي المستخدم والذي يحتوي علي إحدى طرق التسهيلات الحسية العصبية (الانقباض والاسترخاء) والذي يعتمد علي إطالة العضلات المحيطة بالمنطقة القطنية بطريقة الانقباض والاسترخاء مما أدي إلي تحسن ملحوظ عن المجموعة الضابطة 


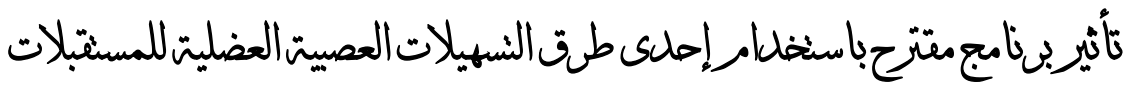
الحسيت للمعابينبآهر أسفل الظلهى

في المدي الحركي للمنطقة القطنية واختفاء الألم حيث جاءت نتائج القوة

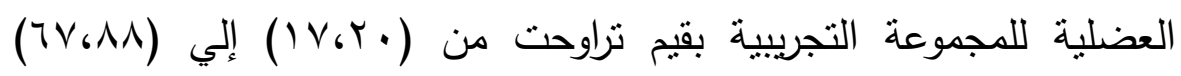
ويرجع أيضًا هذا الفارق في التحسن عن المجموعة الضابطة إلي نتفيذ أيضًا

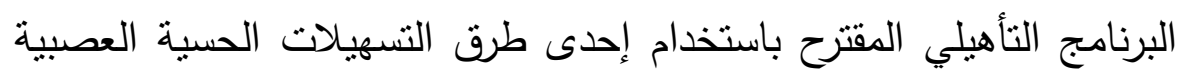

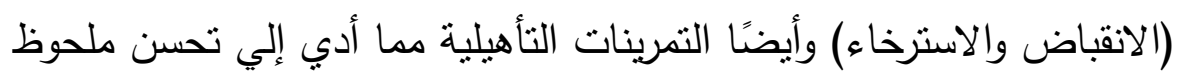
في القوة العضلية والمدي الحركي ومن هنا يكون قد انتهي ظهور الألم الذي الذي التئي

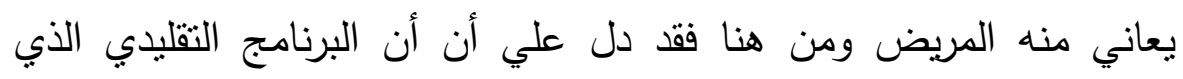

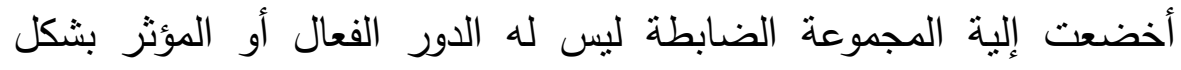
إيجابي في تحسن المدي الحركي والقوة العضلية بينما نلاحظ تحسن ملحوظ في نتائج المدي الحركي والقوة العضلية في منطقة الظهر مقارنة بالمجموعة

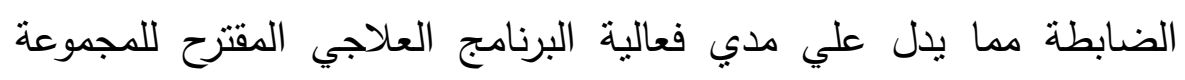
التجريبية .

وهذا يتفق مع بعض الدراسات والبحوث السابقة، مثل دراسة أحمد

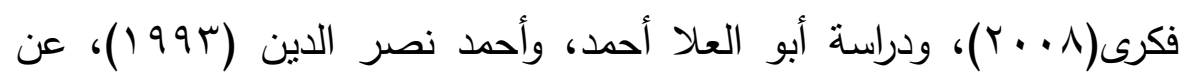

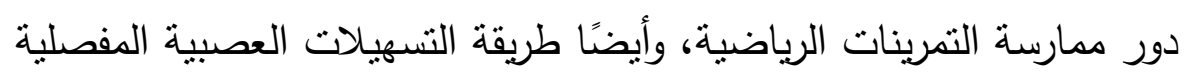
للمسنقبلات الحسية (PNF) فى تتمية المرونة والسعة الانبساطية للعضلات. الاستنتتاجات : من خلال نتائج البحث تم التوصل إلى الاستتناجات التالية: .0 .1$. 


\section{المركن القومي للبحوث التبويةوالتنمية}

ا ـ أدي استخدام البرنامج التأهيلي والذي يشتمل علي تمرينات المستقبلات الحسية العصبية والتمرينات التأهيلية إلي العمل علي تحسن متغيرات البحث . أ- زيادة المدي الحركي للعمود الفقري • ب- زيادة القوة العضلية لعضلات الظهر • ج-زيادة القوة العضلية لعضلات الرجلين • د- زبادة القوة العضلية لعضلات البطن • r. أدي استخدام تمرينات المستقبلات الحسية العصبية للمجموعة التجريبية إلي زيادة المدي الحركي لمنطقة الجذع والعمود الفقري - مان r. أدي استخدام التمرينات التأهيلية للمجموعة التجريبية إلي زبادة القوة العضلية في متغيرات البحث (قوة عضلات الظهر ـقوة عضلات الرجلين ـقوة عضلات البطن ) .

انطلافًا من الاستتاجات المستمدة من العرض والتحليل الإحصائى لبيانات هذا البحث يوصى الباحث بما يلى: ا . عدم تجاهل الألم عند بداية ظهوره والنتخيص المبكر ومحاصرة

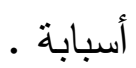




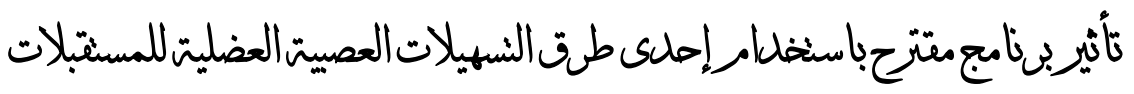
الحسيت للمعابينبآهر أسفل الظلهى

r. الإحاطة التامة بالأسباب المؤدية لآلام أسفل الظهر ومعرفة

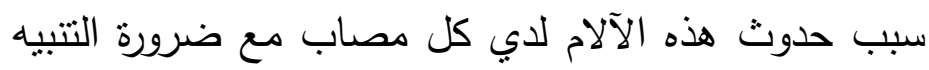

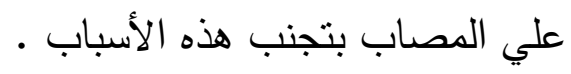

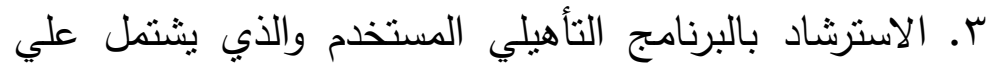

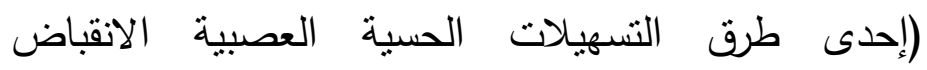
والاسترخاء_ التمرينات التأهيلية ) لآلام أسفل الظهر .

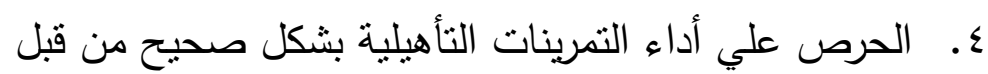
المصابين خاصة غير الرياضيين. ه. يجب أن يسبق الوحدة التأهيلية اليومية وقت كاف من الراحة بعد ممارسة الأعمال اليومية.

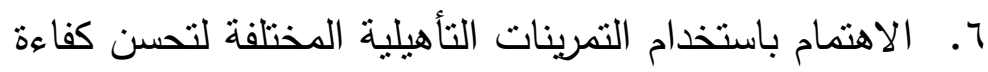
النغمة العضلية وقوة الانقباض والانبساط لعضلات منطقة

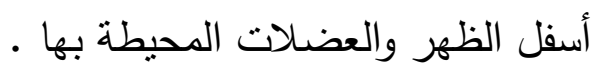




\section{المركن القومي للبحوثالتهبيةوالنمية}

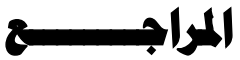

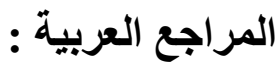

1. أبو العلا أحمد عبد الفتاح، أحمد نصر الدين (ب991م). فسيولوجيا اللياقة البدنية، دار الفكر العربي، القاهرة.

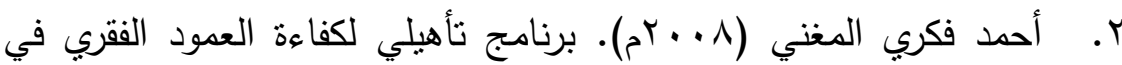
حالات الإصابة بآلام أسفل الظهر، رسالة ماجستير غير منشورة، جامعة

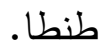

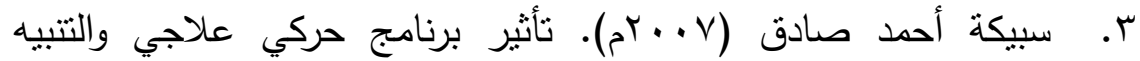
الكهبي علي آلام أسفل الظهر للسيدات غير العاملات بدولة الكويت، رسالة ماجستير غير منشورة، كلية التربية الرياضية للبنين جامعة حلوان.

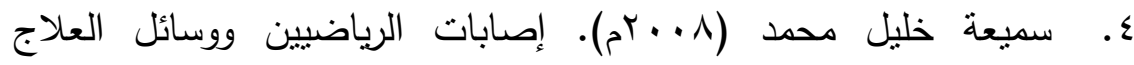
والتأهيل، شركة ناس للطباعة، القاهرة. ه. شريف الدريني هاشم (· ( •rم). تأثير برنامج للتمرينات التأهيلية والعلاج المائي للحد من آلام أسفل الظهر لدي رباعي رفع الأثقال، رسالة ماجستير غير منشورة، كلية التربية الرياضية بنين جامعة حلوان.

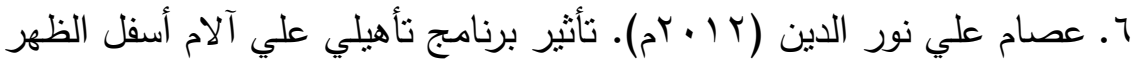
والحالة الصحية بمساعدة النقاط الانعكاسية، رسالة دكتوراة، كلية التربية

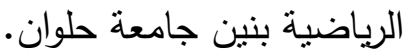
V. محمد قدري بكري، سهام السيد الغري (0. بام). الإصابات الرياضية والتأهيل البدني، طا، دار المنار للطباعة والنشر، القاهرة. 
تأثيربنامج متتّحباسنخلام إحلى طلق النهيلات العصيت العضليت للمسنتبلات الحسيت المصابينبآلامر أسفل الظهى

^. محمد قدري بكري، سهام السيد الغري (·(بام). الإصابات الرياضية والتأهيل البدني،طء، دار المنار للطباعة والنشر، ، القاهرة.

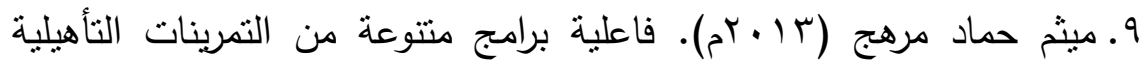

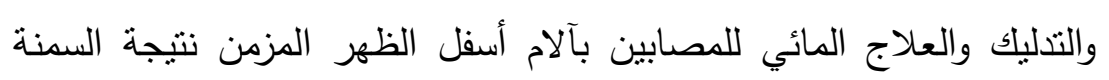

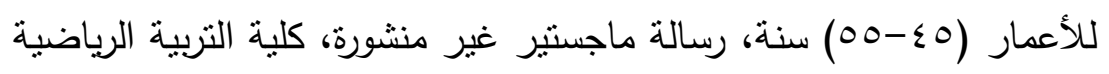
بنين جامعة حلوان.

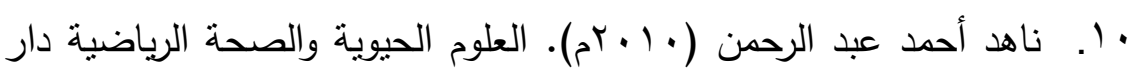

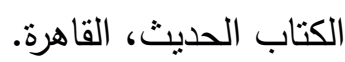

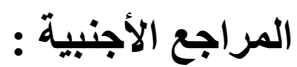

11. Howard Knudsen (2006). Compaction between tests of fatigue and force for trunk flexion, cot lip pin Williams Wilkins com ,U.S.A.

12. Her gun ,c.,Rainville.J.Sobel, J.B, Hipona,M.,(2000). Long term Exercises adherence After intensive Rehabilitation for chronic Low Back Pain Tufts University School of Medicine ,Boston, MA,U.S.A.

13. Jonathan and other(2003). Clinical exercise physiology, human kinetics, N, Y USA.

14. Mark S Wallace, peter S(2005). Stats, pain medicine management, just the fact ,M.C. Grew- hill comp, USA.

15. Nelson et all (1991). Sports medicine physical fitness, Torino Italy, p.p,49-22 seep . 